\title{
Translanguaging in the Case of Bilingual University Students
}

\author{
Ali Alsaawi ${ }^{1}$ \\ ${ }^{1}$ Department of English, College of Humanities \& Sciences in Alghat, Majmaah University, Saudi Arabia \\ Correspondence: Ali Alsaawi, Department of English, College of Humanities \& Sciences in Alghat, Majmaah \\ University, Majmaah, Saudi Arabia. E-mail: a.alsaawi@mu.edu.sa
}

\author{
Received: September 7, 2019 Accepted: October 7, 2019 Online Published: October 28, 2019 \\ doi:10.5539/ijel.v9n6p281 URL: https://doi.org/10.5539/ijel.v9n6p281
}

\begin{abstract}
According to Garcia (2009), translanguaging is “... the act performed by bilinguals of accessing different linguistic features or various modes of what are described as autonomous languages, in order to maximize communicative potential" (p. 140). Therefore, it is more about communication than language use. Bilinguals tend to employ their linguistic repertoire as an integrated communication system. In the context of this study, senior university bilingual students majoring in business in Saudi Arabia are usually competent in their mother tongue (Arabic) and in their additional language (English) due to the nature of business. They are keen to maintain their ability in English as far as possible as they consider themselves "long-term English learners". Today, Saudi Arabia is increasingly building bridges to the outside world and clearly proficiency in English is one such bridge, allowing Saudi Arabia to integrate with English-speaking countries. Stakeholders in Saudi Arabia are now seeking English-proficient applicants for jobs, regardless of their speciality, more so than previously. This has become the norm in both the public and private sectors. However, bilingual university students majoring in business still tend to employ their mother tongue regardless of their proficiency in English. This may indicate their views and feelings with regard to the need to be bilingual in any future work context. This study focuses on senior business students at Majmaah University. Semi-structured interviews were conducted with the students $(n=14)$ and their instructor $(n=1)$. This paper reports on the students' attitudes towards bilingual activities, specifically task-related discussions, and the impact on their communicative repertoire from their perspective.
\end{abstract}

Keywords: translanguaging, communication, business students, Arabic, English

\section{Introduction}

The amalgamation of more than one language in a single discourse is increasingly noticeable, particularly as the world is becoming ever more linked. This practice has been highlighted and discussed using different terms, including code-switching, code-mixing, language choice, language shift and translanguaging. However, although these phenomena have some common elements, they differ in certain respects. For instance, translanguaging is particularly concerned with the exploitation of the speaker's full linguistic repertoire to create meaning. It is seen as a means of eliminating the separation of languages since speakers are able to combine their linguistic repertoires to produce comprehensible meaning. The term "translanguaging" was first employed by William (1994), who used it to refer to the inclusion of two languages in the same context. MacSwan (2017) believes that translanguaging " ... supports a heteroglossic language ideology, which views bilingualism as valuable in its own right” (p. 167).

According to Otheguy, García, and Reed (2018), "The myriad lexical and structural features mastered by bilinguals occupy a cognitive terrain that is not fenced off into anything like the two areas suggested by the two socially named languages" (p. 1). A considerable amount of research conducted by García, MacSwan, Otheguy and Reid has focused on translanguaging with regard to particular languages, namely English and Spanish. However, English and Arabic has not attracted attention as yet with the exception of Palfreyman and Al-Bataineh (2018) and Ayash (2019). Therefore, this paper aims to shed some light on this phenomenon among senior university students in Saudi Arabia, explored qualitatively through interviews in to understand how individuals perceive it. In addition, it explores the students' and their instructor's opinions of translanguaging in the classroom. 


\section{Literature Review}

Translanguaging is a theoretical perspective related to bilingualism and multilingualism. This theory posits that bilinguals employ specific features from their unitary linguistic repertoire to produce comprehensive meaning in communicative contexts. According to Garcia and Wei (2014), it is bilinguals' ability to "... use their semiotic repertoire to act, to know, and to be" (p. 137). This means that it focuses primarily on the communicative purpose shared between interactants. This is what makes translanguaging more pragmatic than similar approaches (i.e., code-switching, code-mixing, language choice, language shift). Pedagogically speaking, translanguaging offers a practical approach to linguistic pedagogy in view of the diversity of students' language practices in language teaching and learning. However, it is argued that translanguaging is primarily concerned with the students' bilingualism, which may consequently affect the traditional stance with regard to preserving and maintaining language separation (García, 2009). Indeed, there has long been dispute among researchers as to whether or not bilingualism affects language separation and therefore language maintenance. In addition, the immersion of translanguaging in the classroom has led to contention among teachers, pedagogical administrators and educational researchers concerning the long-held belief of the need for monolingualism in foreign/second language classrooms (García \& Kleyn, 2016; García \& Wei, 2014; García et al., 2017; Gort \& Pontier, 2013; Gort \& Sembiante, 2015; Mazak \& Carroll, 2017; Paulsrud, Rosén, \& Straszer, 2017).

It is worth mentioning here that translanguaging is not a replacement for similar phenomena, such as code-switching or code-mixing; however, it challenges the code view of language practice. In addition, the deployment of a unitary linguistic repertoire does not necessarily threaten language maintenance and development as they are considered different language practices. Moreover, translanguaging has a positive impact on deepening and fostering the learner's comprehension and understanding of complex content and texts. In turn, the ability of bilinguals to employ their unitary linguistic repertoire in dealing with complicated content will boost and improve their engagement. A recent study conducted by Palfreyman and Al-Bataineh (2018) explored students' attitudes and actual practices in a bilingual Emirati university where English and Arabic are both commonly used. The study revealed that students had very positive views of the inclusion of the two languages as they understood their importance for their future careers. This is a clear indication of how Gulf countries are becoming more pragmatic and open. Another recent ethnographical study conducted by Ayash (2019) where she compared writing programs in Lebanon (Beirut University) and Washington (University of Seattle) to scrutinize the contradictory manifestations of language ideologies. She argued that:

“... there has to be an activist dimension to translingualism in writing pedagogy, which involves a deliberate intervention in taken-for-granted monolingual and multilingual language representations and practices in the FYW classroom in strategic and well-grounded ways" (p. 18).

\subsection{Theoretical Critique of the Unitary Linguistic Repertoire in Translanguaging}

According to Wei (2017), the field of applied linguistics lacks theoretical concepts of its own and instead borrows theories from related fields (e.g., linguistics). However, the borrowed concepts do not relate sufficiently to what is done in applied linguistics and therefore do not reflect ongoing "applied" research. Nonetheless, applied linguistics has always contributed to both practical and theoretical issues as a field of inquiry. These contributions have been detailed by Kramsch (2015). In this context, translanguaging has emerged as a descriptive concept focusing on a particular language practice that promotes a positive stance towards bilingualism. The theoretical view of translanguaging as a linguistic system has been analysed from different perspectives. The first such perspective was articulated by Garcia (2009, p. 140), who categorized translanguaging in terms of three assumptions: (i) that “... it posits that individuals select and deploy features from a unitary linguistic repertoire in order to communicate"; (ii) it "takes up a perspective on bi- and multilingualism that privileges speakers' own dynamic linguistic and semiotic practices above the named languages of nations and states"; (iii) "it still recognizes the material effects of socially constructed named language categories and structuralist language ideologies, especially for minoritized language speakers".

This was then followed by other perspectives, such as that of Otheguy et al. (2015), who argue that “... bilingualism and multilingualism, despite their importance as sociocultural concepts, have no correspondence in a dual or multiple linguistic system" (p. 2). In contrast, MacSwan (2017), critiquing Otheguy et al.'s (2015) argument, proposes “... a multilingual perspective on translanguaging, which acknowledges the existence of discrete languages and multilingualism along with other treasured icons of the field, including language rights, mother tongues, and codeswitching" (p. 169). He then provides a holistic model consisting of three distinctive views on multilingualism, as illustrated in Figure 1. 


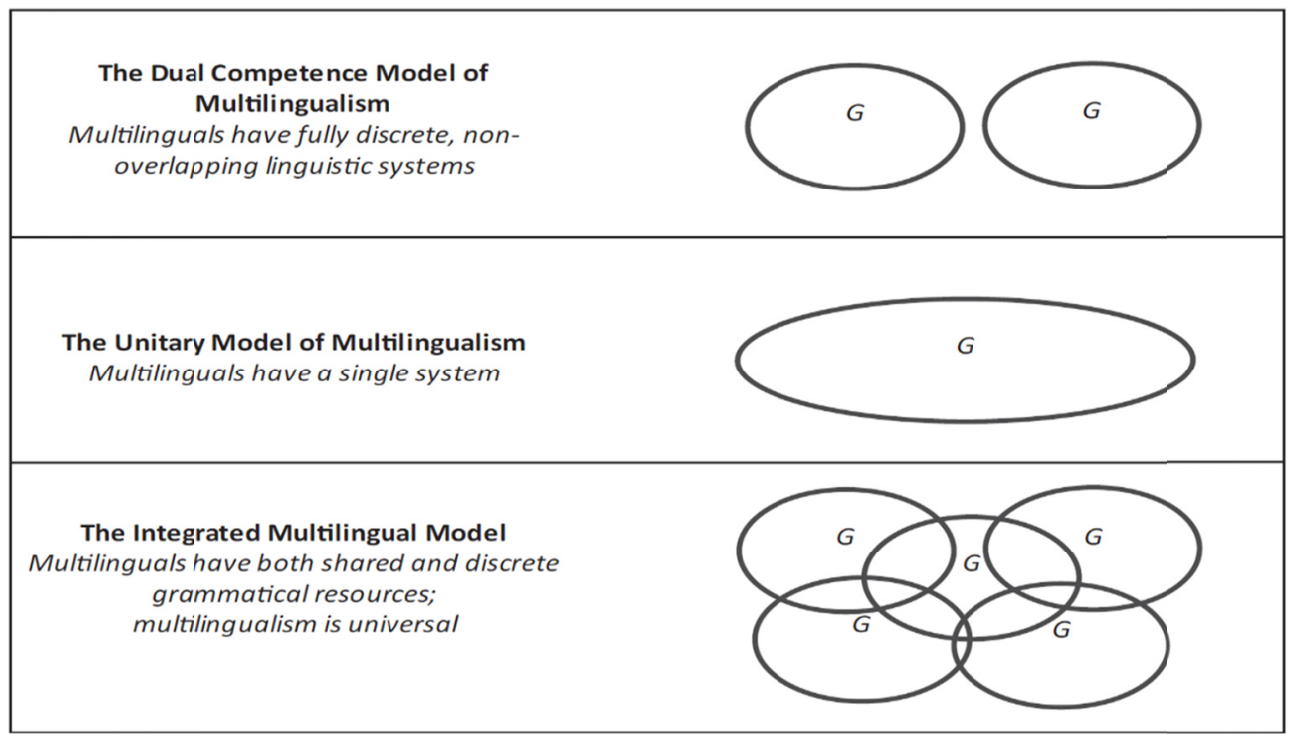

Figure 1. Views of multilingualism (MacSwan, 2017, p. 180)

As is apparent from Figure 1, the dual competence model adopts a view of code-switching in which bilinguals have separate languages. The unitary model, in contrast, treats bilingualism in the same way as monolingualism in that the "... structural knowledge associated with what appear socio-politically as two discrete languages actually reflects a single, internally undifferentiated system" (MacSwan, 2017, p. 179). The integrated model views each linguistic system as distinctive due to some language-specific differences, but with shared resources among other languages. Therefore, we can argue that teachers who adopt a unitary view will generate a much more practical and holistic educational atmosphere as they exploit the learners' whole linguistic repertoire.

\section{Methodology}

The study explored the phenomenon of translanguaging in the context of senior university students majoring in business in Saudi Arabia within an interpretivist paradigm. Within this paradigm, meanings were drawn from the participants' opinions and realities created to understand them, using an inductive approach by which the observer attempts to link particular groups on their own terms and from their own perspectives (Flowers, 2009). This paradigm is associated with qualitative research methods and the study explored the phenomenon of translanguaging qualitatively through semi-structured interviews with both senior business university students at Majmaah University and their instructor. The research questions, which were intended to be exploratory rather than confirmatory, were as follows:

1) What language(s) do students employ during discussions?

2) Do students translanguage in the classroom?

3) Do students support translanguaging in the classroom?

The first question aimed to scrutinize the actual situation in the classroom. Then, the second question addressed whether or not their actual practice could be considered "translanguaging". Following this, the third question explored the students' attitudes towards the phenomenon of translanguaging. The study was undertaken at Majmaah University in Saudi Arabia with senior business students and their teacher. Semi-structured interviews were conducted with 14 students and their instructor. To analyse the data, all audio-recorded interviews were manually transcribed verbatim. Thematic analysis, which is "... a method for identifying, analysing and reporting patterns (themes) within data" (Braun \& Clarke, 2006, p. 79), was adopted, this being one of the most common analytic approaches in qualitative research (Bryman, 2012). The framework comprised "a matrix-based analytic method" (Ritchie et al., 2013, p. 220). I began the analysis by reading the transcripts repeatedly until I became familiar with the accounts. Then, I noted preliminary impressions that I repeatedly noticed. After that, I coded features related to the research questions. These codes were then listed under potential themes. The process is detailed in Table 1. 
Table 1. Analytic procedure

\begin{tabular}{ll}
\hline Stage & Procedure \\
\hline $\mathbf{1}$ & The process began by repeatedly reading the whole transcripts to become familiar with the accounts. \\
$\mathbf{2}$ & I noted preliminary impressions and interpretations in the left margin, while the right margin was left for noting emerging \\
themes.
\end{tabular}

\section{Results and Discussion}

According to the interviews with the students and their instructor, the business students mixed Arabic with English in the classroom to foster comprehension and discuss complicated tasks. The students reported being eager to improve their English as they were aware of the stiff competition ahead of them in terms of employment, especially in the private sector. Moreover, their instructor supported the inclusion of English in the students' curriculum. He believed that business students need to be highly proficient in English as this ability is an important element in the business market. Specifically, out of 14 students, 11 were keen to use English together with their native language (Arabic) in the classroom. For instance, one of the students stated that:

"... including two languages would boost my understanding, especially during group tasks."

Although their proficiency in English was intermediate, they believed in the need for English in their professional future. In addition, another student indicated his awareness about stakeholders' requirement that:

"... the business market often requires English proficiency."

Only two students were not convinced of the value of using English in the classroom, although they knew how important it would be for their future careers. One student welcomed the inclusion of English with Arabic, but would rather English were not used in the classroom due to his low proficiency in English, which (in his opinion) might affect his overall grades:

“... I am in favour of using both languages in the classroom; however, I am afraid it may affect my overall grade which I care most about."

Therefore, it is clear that senior business students are aware of the importance of English for their future careers, especially in the case of those who aim to work in the private sector. The private sector in Saudi Arabia is developing greatly and is opening its doors to the world in an attempt to accelerate interaction with the global market, which is part of Saudi Vision 2030. As the presence of foreign investors and companies is increasing noticeably and English is generally the medium of communication, Saudi business students are highly encouraged to gain proficiency in English.

The teacher clearly encouraged the use of English together with Arabic in the classroom. However, he raised some concerns which could hinder such inclusion. The first was the students' level in English, which could affect their grades. Therefore, the teacher was obliged to limit the use of English to an appropriate level. He reasoned that the reason the students were only at intermediate level in English was because they were focused on their grades and were disregarding the market's needs, i.e., proficiency in English. The second concern was that most business departments in Saudi universities teach mainly in Arabic, which consequently affects the attitudes of students and their level in English. He was strongly of the opinion that the use of English should be maximized in the classroom with a view to preparing business students to join the work force with as little difficulty as possible since English is the medium of interaction in the business market worldwide. Even local business companies in Saudi Arabia are starting to employ English in their operations and most use both English and Arabic in their official documents. In view of this, currently most business departments in Saudi universities are not paying sufficient attention to the need for English in the students' future careers. While business students and teachers are aware of the situation, they are not acting on it. Currently, English is still considered a foreign language in Saudi Arabia and business students at most Saudi universities are taught mainly in Arabic. Business students should be encouraged to learn English as part of studying for their major rather than being expected to 
learn it separately or in the preparatory year. The results of this study are in line with those of Palfreyman and Al-Bataineh (2018), who found positive attitudes towards translanguaging in the United Arab Emirates (UAE), consistent with the need for both English and Arabic in the workforce. Although Saudi Arabia is considered less open than the UAE, it is currently transforming its economic system to allow for more flexible economic and cultural regulations, including the medium of instruction and interaction in the workforce; thus, more openness is gradually becoming the norm. Therefore, I would encourage stakeholders to reassess the importance of English with regard to business students in order to comply with Saudi Vision 2030. This does not mean that Arabic should be excluded from the classroom; rather, both Arabic and English can work together to boost students' comprehension and understanding.

\section{Conclusion}

Translanguaging is a highly effective method allowing bilingual students to use their full linguistic repertoire to foster their comprehension. It is clear that the business students and their instructor in this study were in favour of employing their complete linguistic repertoire (Arabic and English), regardless of their proficiency in English, as the students found it very helpful in comprehending their tasks and also increasing their awareness of the employment requirements for business graduates. Even students with only intermediate proficiency in English preferred to use both English and Arabic in classroom discussions, clearly indicating recognition of the need to maximize their use of English. Stakeholders in education, moreover, are advised to consider flexibility in language use, letting students decide their preferred medium of instruction, particularly for use in discussions in the classroom. In doing so, we will be supporting the students' learning cycle and thus their learning outcomes. It is recommended that further research be conducted using video-recorded observation and with larger samples in the Saudi higher education context to achieve a better understanding of the actual practices of business students and their instructors and the implications for translanguaging.

\section{References}

Ayash, N. B. (2019). Toward Translingual Realities in Composition: (Re)working Local Language Representations and Practices. Utah State University Press.

Braun, V., \& Clarke, V. (2006). Using thematic analysis in psychology. Qualitative Research in Psychology, 3(2), 77-101. https://doi.org/10.1191/1478088706qp063oa

Bryman, A. (2012). Social research methods. Oxford: Oxford University Press.

Flowers, P. (2009). Research philosophies-importance and relevance. European Journal of Information Systems, $3(2), 112-126$.

García, O. (2009). Chapter 8 Education, multilingualism and translanguaging in the 21 st century. In T. Skutnabb-Kangas, R. Phillipson, A. K. Mohanty \& M. Panda (Eds.), Social Justice Through Multilingual Education (pp. 140-158). https://doi.org/10.21832/9781847691910-011

García, O., Johnson, S. I., Seltzer, K., \& Valdés, G. (2017). The translanguaging classroom: Leveraging student bilingualism for learning. Philadelphia, PA: Caslon.

García, O., \& Kleyn, T. (eds.). (2016). Translanguaging with multilingual students. New York and London: Routledge. https://doi.org/10.4324/9781315695242

García, O., \& Wei, L. (2014). Translanguaging. The Encyclopedia of Applied Linguistics, 1-7. https://doi.org/10.1057/9781137385765

Gort, M., \& Pontier, R. (2013). Exploring bilingual pedagogies in dual language preschool classrooms. Language and Education, 27, 223-245. https://doi.org/10.1080/09500782.2012.697468

Gort, M., \& Sembiante, S. F. (2015). Navigating hybridized language learning spaces through translanguaging $\begin{array}{lllll}\text { pedagogy. International Multilingual Research Journal, } & \text { 9, }\end{array}$ https://doi.org/10.1080/19313152.2014.981775

MacSwan, J. (2017). A multilingual perspective on translanguaging. American Educational Research Journal, 54(1), 167-201. https://doi.org/10.3102/0002831216683935

Mazak, C. M., \& Carroll, K. S. (eds.). (2017). Translanguaging in higher education: Beyond monolingual ideologies. Bristol, UK: Multilingual Matters. https://doi.org/10.21832/9781783096657

Otheguy, R., García, O., \& Reid, W. (2015). Clarifying translanguaging and deconstructing named languages: A perspective from linguistics. Applied Linguistics Review, 6(3), 281-307. https://doi.org/10.1515/applirev-2015-0014 
Otheguy, R., García, O., \& Reid, W. (2018). A translanguaging view of the linguistic system of bilinguals. Applied Linguistics Review, 10(4). https://doi.org/10.1515/applirev-2018-0020

Palfreyman, D. M., \& Al-Bataineh, A. (2018). This is my life style, Arabic and English: students' attitudes to (trans) languaging in a bilingual university context. Language Awareness, 27(1-2), 79-95. https://doi.org/10.1080/09658416.2018.1431244

Paulsrud, B. A., Rosén, J., Straszer, B., \& Wedin, A. (eds.). (2017). New perspectives on Translanguaging and education. Bristol, UK: Multilingual Matters. https://doi.org/10.21832/9781783097821

Poza, L. E. (2018). The language of ciencia: Translanguaging and learning in a bilingual science classroom. International Journal of Bilingual Education and Bilingualism, 21(1), 1-19. https://doi.org/10.1080/13670050.2015.1125849

Ritchie, J., Lewis, J., Nicholls, C. M., \& Ormston, R. (Eds.). (2013). Qualitative research practice: A guide for social science students and researchers. Sage.

Wei, L. (2017). Translanguaging as a practical theory of language. Applied Linguistics, 39(1), 9-30. https://doi.org/10.1093/applin/amx039

\section{Copyrights}

Copyright for this article is retained by the author, with first publication rights granted to the journal.

This is an open-access article distributed under the terms and conditions of the Creative Commons Attribution license (http://creativecommons.org/licenses/by/4.0/). 